RESEARCH PAPER

\title{
Suffering Silence and Turnover Intentions while Exposed to Workplace Bullying: The Role of Psychological Distress
}

\author{
Ghulam Abbas Bhatti ${ }^{1}$ Alia Ahmed 2
}

1. Ph. D Scholar, School of Business Administration, National College of Business Administration and Economics, Lahore, Punjab, Pakistan

2. Dean \& Professor, School of Business Administration, National College of Business Administration and Economics, Lahore, Punjab, Pakistan

\begin{tabular}{|c|c|}
\hline PAP & \\
\hline $\begin{array}{l}\text { Received: } \\
\text { March 14, } 2021 \\
\text { Accepted: } \\
\text { June 25, } 2021 \\
\text { Online: } \\
\text { June 30, } 2021\end{array}$ & $\begin{array}{l}\text { is a well-focused phenomenon in } \\
\text { specific way it unfolds in non- } \\
\text { ally in their higher education sector } \\
\text { n response to this gap, an empirical } \\
\text { cross higher education institutions }\end{array}$ \\
\hline $\begin{array}{l}\text { ds: } \\
\text { gical } \\
\text { havior, }\end{array}$ & $\begin{array}{l}\text { ategies sufferers could employ } \\
\text { llying. Data were collected fron }\end{array}$ \\
\hline $\begin{array}{l}\text { *Corresponding } \\
\text { Author }\end{array}$ & $\begin{array}{l}\text { nediating role of distress between bullying and its venomous } \\
\text { onsequences. In brief, this paper recommends effectually } \\
\text { mplemented anti-bullying policy and management support to } \\
\text { lleviate adversative impact of workplace bullying on academic } \\
\text { aculty working in higher education institutions }\end{array}$ \\
\hline
\end{tabular}

\section{Introduction}

Workplace bullying (WPB) is the continuous exposure to undesirable conduct by others in the workplace (Einarsen et al., 2011), especially by those on managing positions (D'Cruz and Rayner, 2013) triggered by unequal relationship based on age, position, influence, status, and capabilities (Yao et al., 2020b). Moreover, such victims can neither express themselves freely nor hold different opinions from the perpetrators. In actuality, WPB bears specific characteristics that intrude the work of others including intimidation, humiliation, and criticism, as overt bullying and unnecessary assignments, cold violence, and discourteous dealing as covert bullying (Escartin et al., 2011; Rai \& Agarwal, 2018; Yao et al., 
2020b). Koon and Pun (2018) have also revealed bullying as an antecedent of insulting behaviors in the workplace.

Previous studies demonstrate that numerous adversarial experiences (e.g. bullying and household dysfunction) at the workplace cause a high level of psychological distress (PD) (Barth et al., 2007; Iranzo et al., 2019; Xu et al., 2018). Likewise, the latest study by Garaigordobil \& Machimbarrena (2019) has also revealed bullying as an antecedent of PD. Decker (1997) described psychological distress as lacking eagerness, facing difficulty in sleep, downheartedness, hopelessness about the future, and feeling emotionally tired or bearing thoughts of suicide. Unfortunately, the dilemma of bullying remained comparatively undiscovered and unresolved in the Asian setting because of victims' specific mindset of feeling embarrassed if exposed as psychologically ill as a result of psychological distress (Aazami et al., 2015; Ismail et al., 2015).

Further, previous studies reveal that WPB damages the working capacity of the existing employees, groups, and organizations (Rahm et al., 2019) and is found directly linked with compromised psychological wellbeing, increased stress level, and worst psychological warnings (Ngale, 2018). For instance, it may increase their turnover intention (TI) and harm their mental and physical health (Magee et al., 2017; Choi et al., 2018; Finstad et al., 2019). ). Also, compromised well-being is observed escalating employees' TI (Fontes et al., 2019). Tett and Meyer (1993) described leave intention as the last cognitive thought intending to leave the current job and looking for new jobs. Salin and Notelaers (2017) necessitated readdressing the premature association between TI and WPB. Likewise, a study in Australia exposed that most of the bullied employees take it worthwhile to leave their jobs as an effective coping strategy against WPB (Ahmad \& Sheehan, 2017, pp. 90-91) while it will be bigoted to underestimate the larger cost of actual turnover associated with the process of recruitment and training (Agarwal \& Gupta, 2018; Wright \& Huang, 2012).

Further, high turnover intentions compel organizations to face the trouble of shortage of skilled human capital as well (Agarwal \& Gupta, 2018).Moreover, Rai and Agarwal (2018) echo the call with a review of Indian employees and discovered that bullied employees think that the organization remains unsuccessful to justify its psychological agreement with them and consequently adopt silent behavior as a passive coping strategy. Employees silence (ES) recognized employees specific coping approach based on concealing the organizational facts to people who can improve the circumstances (Morrison \& Milliken, 2000; Pinder\&Harlos, 2001; Knoll \& Dick, 2013; Whiteside \& Barclay, 2013; Prouska\&Psychogios, 2018).

This paper attempts to extend the existing research to completely understand the association between WPB and ES as to the best of our knowledge, a dearth of knowledge exists in revealing the complete mechanism (Rai \& Agarwal, 2018; Yao et al., 2020b). Bullying has been observed as commonly prevailing among academics even though not as comprehensively examined as required (Mahmoudi, 2019). 
Further, detrimental outcomes of WPB are exclusively seeming in the higher education sector (Desrayaud et al., 2018), but we find limited reports (Keashly \& Neuman, 2013). The extant literature on academic bullying found that about twentyfive percent of academic staff was bullied within one year, while forty to fifty percent viewed others as being victimized (Keashly, 2021). Given the scarcity of evidence about WPB among higher education academic faculty in Pakistan, the outcomes of this study will be valuable for higher education executives.

\section{Literature Review and Hypotheses}

\section{Workplace bullying (WPB) and Employee Silence (ES)}

Previous studies have revealed that ES has become very common regardless of its extremely dysfunctional nature (Morrison, 2014). The dysfunctionality of silence includes poor commitment, disappointment, pessimism, and low innovation, etc. (Knoll \& Dick, 2013a; Tangirala\&Ramanujam, 2008; Vakola\&Bouradas, 2005; Wang \& Hsieh, 2013). In the same lines, it has been discovered that silence creates damage to the organizations because of employees nature to withhold the critical information required to identify and resolve the problem in a timely fashion (Morrison \& Milliken, 2000; Milliken \& Morrison, 2003; Tangirala\&Ramanujam, 2008). Therefore, Dedahanov et al. (2015) stressed finding the reasons behind ES to prevent further damage.

Importantly, the selection of examining the relationship between WPB and ES has been driven by few very important calls including a recent qualitative inquiry by Rai and Agarwal (2017b) based on the argument that perpetrator's superior organizational position (Einarsen et al., 2011) creates power disparity. Correspondingly, to have a safe standing, employees are found motivated to keep silent behavior (Milliken et al., 2003). Drawing upon COR Theory (Hobfoll, 1989), we hypothesize that WPB generates a procedure of resource loss, and workers are likely to decide to remain silent to guard and preserve their residual resources. Based on the above discussion, we may propose that;

H1: WPB is positively associated with employees' silence.

\section{Workplace Bullying (WPB) and Turnover Intentions (TI)}

Past researches reveal that the toxic environment created by WPB obstinately exposes workers to undesirable and hostile behaviors from one or more co-workers and unfortunately, it becomes difficult for them to escape because of their less powerful status in comparison with the perpetrators (Einarsen et al., 2011). It has been discovered that WPB is a vigorous process that accelerates over time while leaving its victims helpless (Ahmad \& Sheehan, 2017; Leymann\&Gustafsson, 1996; Samnani, 2013). Eventually, such victims of bullying when finding themselves in a state of helplessness used to mature a state of mind towards willingly leaving the job to avoid such noxious interfaces (Abubakar, Megeirhi\&Shneikat, 2018; Salin \& 
Notelaers, 2020).Considering previous results, WPB has been discovered to decrease employees' job satisfaction increase psychological strain and enhances their feelings of intention to leave (Van Dyk, 2016). The same thing has been observed by Charilaos et al. (2015) who claimed a positive association between WPB and employees' TI.

While drawing upon COR theory (Hobfoll, 1989) we may propose that when employees are subjected to loss of psychological resources, following a threat of WPB, they are moved to safeguard themselves from more loss by way of coping but when they are not able to find any effective coping mechanism, they consider leaving the job as an alternative coping approach to guard their diminishing resources against more loss. Based on the above discussion, we may propose that;

H2: Workplace bullying is positively associated with employees' turnover intention.

\section{Psychological Distress (PD) as a mediator between Workplace Bullying (WPB) and Employees Silence (ES)}

Past studies show that bullying victims are found suffering from severe adverse psychological health issues (Verkuil et al., 2015). Moreover, Einarsen and Nielsen (2014) found that victims of WPB were 1.77 times more likely to exhibit PD in association with those who were not victimized. Interestingly, recent studies are progressively addressing WPB as a major contributing factor for distress at work causing reduced well-being and damaging work behaviors (Attell, Brown \& Treiber, 2017). The positive association between WPB and PD is further supported by Einarsen and Nielsen (2015) and the same phenomenon is explained by Verkuil et al. (2015) who revealed that WPB is an antecedent of PD.

$\mathrm{Xu}$ et al. (2015) discovered that abused employees (including those who are psychologically distressed) experience emotional exhaustion, which purposefully persuades them to remain silent. COR theory also explains the same relationship of PD and ES (Ng \& Feldman, 2012; Xu et al., 2015) and argues that psychologically distressed individuals try to save their residual resources by avoiding confrontation with the perpetrators while calculatingly consider the potential costs and benefits associated with voice and most often choose to remain silent (Kish- Gephart et al., 2009). The same findings are presented by Ng and Feldman (2012) who submitted that distressed persons lean towards withholding their ideas to guard the residual psychological resources. Based on the above discussion we may propose that;

H3: Psychological distress (PD) mediates the relationship between workplace bullying (WPB) and employee silence (ES).

\section{Psychological Distress (PD) as a mediator between Workplace Bullying (WPB) and Turnover Intention (TI)}

Tsuno et al. (2017) have suggested that WPB not only affects individuals but is directly involved in hurting team dynamics. Undeniably, previous studies linked 
adverse workplace events to PD including WPB as one of the major events (Garaigordobil \& Machimbarrena, 2019; Halpern et al., 2017; Iranzo et al., 2019; Xu et al., 2018). Moreover, past researches argued that there is a need to re-address the severity of the problem of workplace bullying in terms of its damaging effects on employees' outcomes through the consequential role of PD (Aazami et al., 2015; Ismail et al., 2015).

Scholars explained that victims of WPB generally experience PD (Hogh, Mikkelsen\& Hansen, 2011) because of the feeling of defenselessness and ineffectiveness which persuade them to be socially isolated at work (LutgenSandvik, 2006; Einarsen et al, 2003). Furthermore, this state of PD ensuing from the sustained phenomenon of WPB has been observed linked with high TI (Glaso et al., 2011).Remarkably, acts of WPB seem harmfully affecting the accomplishment of psychological needs triggering higher TI (Van Dyk, 2016). While Dysvik and Kuvaas (2010) further elaborated that nonfulfillment of psychological needs initiates distress that further results in employees' lowered intrinsic motivation. Further, lowered intrinsic motivation is meaningfully linked with employees' TI (Shareef \&Atan, 2019).

Based on the COR theory, we may propose that PD will be the predictable response of individuals when they will be exposed to WPB because it will be taken as a threat to their available resources (Hobfoll, 2001). Considering such harmful effects of PD, and in line with COR theory, we may propose that victims of WPB may cogitate quitting the job as a coping mechanism to safeguard their diminishing well-being resources from extra loss as a result of PD. Based on the above discussion, we may predict that,

H4: Psychological distress (PD) mediates the relationship between workplace bullying (WPB) and employee turnover intentions (TI).

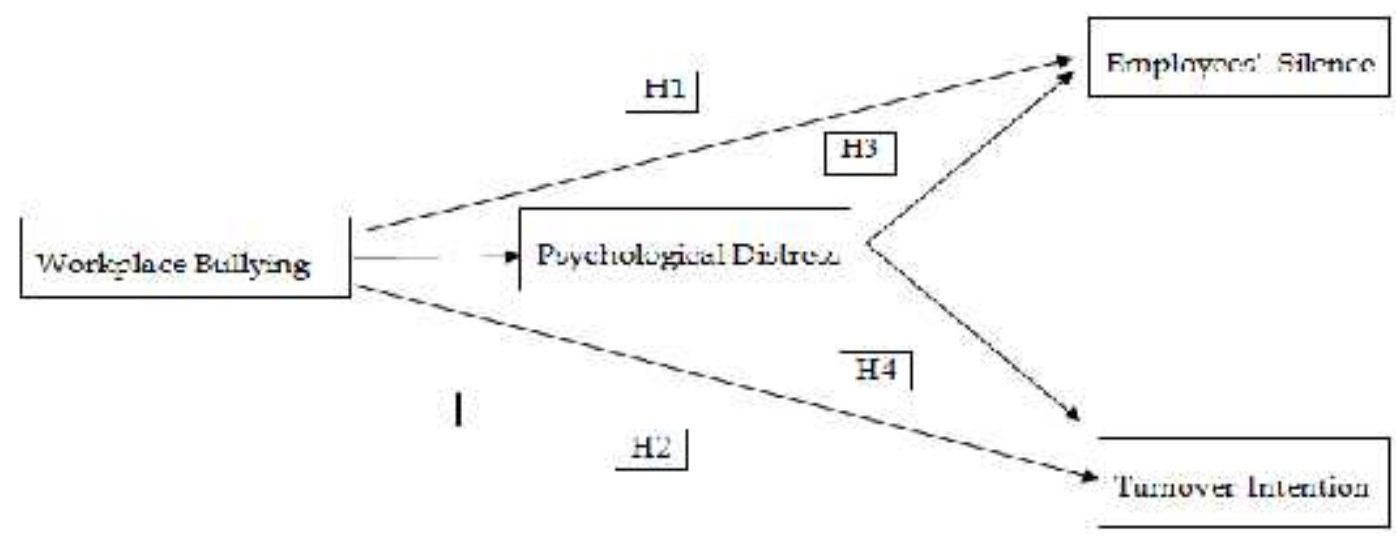

Figure 1: Theoretical Model

\section{Material and Methods}




\section{Procedures and Participants}

In the current study, a survey-based questionnaire was considered most suitable for data collection because of the requirements of the study to understand the impact of WPB on feelings, attitudes, and behaviors of higher education faculty members of different recognized universities from HEC of Pakistan working in different major cities in province Punjab through convenience sampling. Common method bias was removed adopting a two-wave time-lagged structure with a gap of one month. Data were gathered for WPB, PD, and control variables at time 1, while responses for ES and TI were collected at Time 2. More precisely, based on the sample frame of the study, 500 questionnaires were distributed using both physical and online mediums of communication. 380 faculty members responded to the questionnaires and the response rate was $76 \%$. However, at the time of the data entry, 350 questionnaires were found completely filled and were used for analysis.

\section{Measures}

\section{Workplace Bullying (WPB)}

WPB was measured using the Negative Acts Questionnaire (NAQ-R). It is a 22-item WPB measure established and thoroughly endorsed by Einarsen, Hoel and Notelaers (2009).

\section{Psychological Distress (PD)}

PD was measured using the K6 (Kessler et al., 2002). The K6 comprises 6 items found steadily increasing the intensity of severity concerning psychosocial and emotional factors.

\section{Employees Silence (ES)}

Five items adapted from Van Dyne et al. (2003) were used to measure ES. The sample item of the scale included "I chose to remain silent when I have concerns about the work."

\section{Turnover Intentions (TI)}

TI was assessed by five items used in Norwegian settings by Dysvik and Kuvaas (2010) who reported Cronbach's alphas for turnover intention $(\alpha=.89)$ that indicated that this scale had acceptable internal consistency reliability. The sample item of the scale included "I often think about quitting my present job."

\section{Control Variables}

Gender, age, education, tenure, and marital status are controlled to minimize their perplexing effects (Bouckenooghe et al., 2015).

\section{Data Analysis.}


The respondents consisted of 235 (67\%) males and 115 (33\%) females. Employees spent 5.4 years ( $\mathrm{SD}=4$ years) as an average time with the current employer. Moreover, $70 \%$ of the respondents were married while $27 \%$ were single, $1 \%$ were widowed and $0.08 \%$ found divorced (see table $1 \& 2$ ).

Table 1

Gender of the Respondents

\begin{tabular}{ccccc}
\hline Gender & Male & Female & Transgender & Total \\
\hline $\mathrm{N}$ & 235 & 115 & 0 & 350 \\
\hline Percentage & $67 \%$ & $33 \%$ & $0 \%$ & $100 \%$ \\
\hline
\end{tabular}

Table 2

Marital Status of the Respondents

\begin{tabular}{cccccc}
\hline $\begin{array}{c}\text { Marriage } \\
\text { Status }\end{array}$ & Married & Unmarried & Widowed & Divorced & Total \\
\hline $\mathrm{N}$ & 245 & 96 & 6 & 3 & 350 \\
\hline Percentage & $70 \%$ & $27 \%$ & $1 \%$ & $0.08 \%$ & $100 \%$ \\
\hline
\end{tabular}

Additionally, $1 \%$ of faculty was found keeping Master Degree while 80 percent faculty were found keeping MS/MPhil as their terminal degree. Additionally, 17 percent were found PhDs (see Table 3).

Table 3

Qualification of Respondents

\begin{tabular}{cccccc}
\hline Qualification & Masters & MS/MPhil & PhD & Post-PhD & Total \\
\hline N & 5 & 280 & 60 & 2 & 350 \\
\hline Percentage & $1 \%$ & $80 \%$ & $17 \%$ & $0 \%$ & $100 \%$ \\
\hline
\end{tabular}

Moreover, while discussing the age factor it is worthwhile to notice that the maximum number of respondents were found in the range of 30-39 years i.e. equal to $52 \%$, and their lowest number was found in the range of $60-69$ years i.e. only $0.05 \%$ (see table. 4 ).

Table 4

Age of the Respondents

\begin{tabular}{ccccccc}
\hline Age & $\mathbf{2 0 - 2 9}$ & $\mathbf{3 0 - 3 9}$ & $\mathbf{4 0 - 4 9}$ & $\mathbf{5 0 - 5 9}$ & $\mathbf{6 0 - 6 9}$ & Total \\
\hline $\mathrm{N}$ & 119 & 183 & 40 & 6 & 2 & 350 \\
\hline Percentage & $34 \%$ & $52 \%$ & $11 \%$ & $1 \%$ & $0.05 \%$ & $100 \%$ \\
\hline
\end{tabular}

Sample characteristics were further explored through the values of mean and standard deviation. The means values for WPB, PD indicate that most respondents were low on workplace bullying and psychological distress. Likewise, the mean score for silence behavior and turnover intentions also shows that most of the higher education teaching faculty experienced low silence behaviors and turnover intentions (see table 5). 
Table 5

Descriptive Statistics

\begin{tabular}{ccccc}
\hline Variables & Minimum & Maximum & Mean & Std. Deviation \\
\hline Workplace Bullying & 1 & 4.82 & 1.9319 & 0.73701 \\
\hline Psychological Distress & 1 & 4.83 & 2.455 & 0.74545 \\
\hline Silence Behavior & 1 & 5 & 2.7243 & 0.83828 \\
\hline Turnover Intentions & 1 & 5 & 2.9276 & 0.94248 \\
\hline
\end{tabular}

Reliabilities of all scales were verified using Cronbach's Alpha which showed that measures were consistent enough to be used for further interpretations (see table.6)

Table 6

Scale Reliabilities

\begin{tabular}{ccc}
\hline Variables & Items & Cronbach's Alpha \\
\hline Workplace Bullying & 22 & 0.937 \\
\hline Psychological Distress & 6 & 0.754 \\
\hline Silence Behavior & 5 & 0.772 \\
\hline Turnover Intention & 5 & 0.847 \\
\hline
\end{tabular}

Primary testing of the research hypotheses was performed through correlational analysis. The correlation matrix determines that all study variables have significant positive correlations with each other (see Table 7).

Table 7

Correlations among study variables

\begin{tabular}{lllll}
\hline \multicolumn{1}{c}{ Variables } & $\mathbf{1}$ & $\mathbf{2}$ & $\mathbf{3}$ & $\mathbf{4}$ \\
\hline 1-Workplace Bullying & 1 & & & \\
\hline 2-Psychological Distress & $.569^{* *}$ & 1 & & \\
\hline 3-Silence Behavior & $.313^{* *}$ & $.438^{* *}$ & 1 & \\
\hline 4-Turnover Intention & $.286^{* *}$ & $.374^{* *}$ & $.345^{* *}$ & 1 \\
\hline${ }^{* *}$ showing 0.01 level of significance (2-tailed), $\mathrm{N}=350$ & & \\
\hline
\end{tabular}

\section{Results and Discussion}

\section{Confirmatory Factor Analysis}

Although the constructs are well established and rigorously tested in the previous researches still we examined their discriminant validity and performed confirmatory factor analyses using AMOS 24 . We found satisfactory indices of the goodness of fit for our measurement model including the value of Chi-square or degree of freedom as less than 3 which is claimed as a good fit by Hooper, Coughlan, and Mullen (2008). Moreover, we found that the comparative fit index (CFI) was greater than 0.80 and standardized root mean square residual (SRMR) was less than 
0.90, demonstrating a good fit as claimed by $\mathrm{Hu}$ and Bentler (1999). A reasonable fitness of the model was also proved based on an index of root mean square error of approximation (RMSEA) that lied between 0.08 and 0.10 (Hooper, Coughlan \&Mullen, 2008) (see table 8).

Table 8

Goodness of Fit Index

\begin{tabular}{cccccccc}
\hline Model & $\chi^{2}$ & Df & $\chi^{2} / \mathbf{d f}$ & CFI & SRMR & RMSEA & Sig \\
\hline Full measurement model & 1400 & 648 & 2.161 & 0.86 & 0.063 & 0.058 & $\mathrm{p}<.001$ \\
\hline
\end{tabular}

It is worthwhile to discuss that Hypothesis 1 was supported by Linear regression analysis (see Table 9) that shows that WPB has a positive relation with PD $(\beta=0.53, p<0.01)$. Moreover, hypothesis 2 was also supported where results show that WPB has a positive relation with ES $(\beta=0.43, p<0.01)$. Further, we also found support for hypothesis 3 that predicted that there would be a positive relationship between WPB and employee TI $(\beta=0.28, \mathrm{p}<0.01)$.

Table 9

Hypotheses testing through regression

\begin{tabular}{cccc}
\hline Associations & B & S.E & p-value \\
\hline $\mathrm{WB} \longrightarrow \mathrm{PD}$ & 0.53 & 0.052 & 0.000 \\
\hline $\mathrm{WB} \rightarrow \mathrm{SB}$ & 0.43 & 0.07 & 0.000 \\
\hline $\mathrm{WB} \longrightarrow \mathrm{TI}$ & 0.28 & 0.079 & 0.000 \\
\hline
\end{tabular}

For the examination of mediating role of PD between WPB and ES as predicted by hypothesis 4, Baron and Kenny's (1986) approach was used and we observed that the value of WPB remained significant showing partial mediation (see table 10) while supporting hypothesis 4 .

Table 10

Mediating Role of PD between WPB and Employees' silent behavior

\begin{tabular}{cccc}
\hline & $\mathbf{M 1}(\boldsymbol{\beta})$ & $\mathbf{M} 2(\boldsymbol{\beta})$ & $\mathbf{M} \mathbf{( \beta )}$ \\
\hline Control Variables & & & \\
\hline Gender & $0.026^{* *}$ & $0.028^{* *}$ & 0.026 \\
\hline Age & $-.027^{* * *}$ & $-.016^{* *}$ & $-.018^{* *}$ \\
\hline Qualification & -0.18 & -195 & -0.16 \\
\hline R2 & 0.077 & \\
\hline Independent Variable & & $0.27^{* *}$ \\
\hline WPB & $0.38^{* * *}$ & \\
\hline R2 & 0.148 & \\
\hline$\Delta R 2$ & 0.074 & $0.23^{* *}$ \\
\hline Mediating Variable & & 0.174 \\
\hline PD & & 0.025 \\
\hline R2 & &
\end{tabular}


In the same lines as discussed above, for the examination of mediating role of PD between WPB and employees TI as predicted by hypothesis 5, Baron and Kenny's (1986) approach was used and we observed that the value of WPB becomes insignificant showing full mediation (see table 11) while supporting hypothesis 5.

Table 11

Mediating Role of PD between WPB and Turnover Intention

\begin{tabular}{|c|c|c|c|}
\hline & $\operatorname{M1}(\beta)$ & M2 ( $\beta)$ & M3 ( $\beta)$ \\
\hline \multicolumn{4}{|c|}{ Control Variables } \\
\hline Gender & -0.043 & -0.019 & -0.092 \\
\hline Age & $-.017^{* *}$ & -0.012 & -0.011 \\
\hline Qualification & 0.042 & 0.022 & 0.04 \\
\hline $\mathrm{R} 2$ & 0.014 & & \\
\hline \multicolumn{4}{|c|}{ Independent Variable } \\
\hline WPB & & $0.23^{* * *}$ & 0.05 \\
\hline $\mathrm{R} 2$ & & 0.036 & \\
\hline$\Delta \mathrm{R} 2$ & & 0.022 & \\
\hline \multicolumn{4}{|c|}{ Mediating Variable } \\
\hline PD & & & $0.33^{* * *}$ \\
\hline $\mathrm{R} 2$ & & & 0.088 \\
\hline$\Delta \mathrm{R} 2$ & & & 0.052 \\
\hline
\end{tabular}

\section{Discussion}

Our study outcomes suggest that WPB has a positive relationship with employees silence and their TI. Further, an indirect magnified impact of WPB on the both above-mentioned dependent variables is proved through PD as a mediating variable. It is proved that PD depicts a mediation effect between bullying-silence and bullying-turnover intention relationships. This study tried to inspect the relationship of 'WPB' with ' $\mathrm{TI}^{\prime}$ as well. Interestingly, we found our outcomes consistent with the study of Anjum and Muazzam (2018) who found that WPB positively and meaningfully projected TI among teachers and also bullied teachers revealed expressively high intentions to leave their works as compared to those who never confronted WPB. Additionally, it was also aimed to discover the mediating role of PD between WPB and TI; WPB and ES and remarkably was found consistent with empirical evidence where WPB was claimed to result in losing brilliant and skilled employees by resulting in their silent behavior and intentions to leave the organization. Furthermore, Coetzee and Dyk (2018) supported the same argument and claimed that WPB was meaningfully related to low energy levels and devotion which in turn were related to a high rate of TI.

\section{Theoretical Contribution}

This study is one of the limited efforts to empirically observe the bullyingsilence and bullying turnover association through PD in the Pakistani setting. The 
current study has discovered thatculture-based on high power distance will be less persuaded to encounter the bosses'unsuitable approaches as, in such cultures, speaking up is reflected as humiliating the super-ordinates, therefore, employees are expected to get themselves settled even being badly victimized by WPB (Mischel\&Shoda, 1995; Guchait et al., 2016, 2019).Resultantly a passive and submissive approach (employees' silence) is expected to confront the managerial heads (Kirkman et al., 2009) or intention to leave will be the alternative strategy. Moreover, COR Theory has been found widely addressing stress-related studies, but its application to WPB is limited (Glambek et al., 2014; Yao et al., 2020b). Importantly, our study has gone through a whole process of "event-cognitionaffective-behavior" (Mischel\&Shoda, 1995; Ayduk\&Gyurak, 2008; Lee \& Pee, 2015; Frieder et al., 2018; Kell, 2018) where PD plays a separate mediating role between WPB and ES, and further WPB and TI.

\section{Managerial Implications}

Apart from theoretical contributions, this study has been expected to discover the practical implications for the practitioners and the academicians as well. We are expecting that our study will support needed developments in the academic workplaces in both public and private universities. The study will motivate the education gurus to understand the importance of loss of higher education institutions because of poor supervisor and peer support, high PD, enhanced level of intention to quit, and inferior work assignation associated with WPB (Tsuno et al., 2017).Practically this study will help the academic gurus to work on the enhancement needed to minimize and discourage the leave intentions and silent behaviors of academic faculty after coping with the intensity of WPB

\section{Limitations and Directions for future research}

We have observed certain limitations which may offer openings for future research. First, our research population belongs only to the higher education sector located in the province of Punjab, Pakistan. Therefore, our study outcomes might not be suggestive for the rest of the business and non-business sectors. Henceforward, upcoming studies can effort to take a broad view to other sectors as well. Second, the response based on gender differences rise another apprehension about the generalizability of our study outcomes. Thus, the forthcoming study should assess the current study with a mainly female population. Third, a larger sample size should be investigated in the upcoming attempts. Fourth, longitudinal and experimental designs can be further proceeded to test for causality among study variables. Further, the potential moderators for the projected relationships can be assessed to track this line of investigation to progress knowledge in both the CSR and the positive psychology literature. 


\section{References}

Ahmad, S., \& Sheehan, M. J. (2017). Understanding the lived experience of bullying in Australian workplaces: An interpretative phenomenological analysis.Journal of Workplace Behavioral Health, 32(2), 74-98.

Ayduk, Ö.,\&Gyurak, A. (2008). Applying the cognitive-affective processing systems approach to conceptualizing rejection sensitivity. Social and personality psychologycompass, 2(5), 2016-2033.

Abubakar, A. M., Megeirhi, H. A., \&Shneikat, B. (2018). Tolerance for workplace incivility, employee cynicism and job search behavior. The Service Industries Journal, 38(9-10), 629-643.

Aazami, S., Shamsuddin, K., Akmal, S., \&Azami, G. (2015). The relationship between Job satisfaction and psychological/physical health among Malaysian working women. TheMalaysian journal of medical sciences: MJMS, 22(4), 40.

Baron, R. M., \& Kenny, D. A. (1986). The moderator-mediator variable distinction in Social psychological research: Conceptual, strategic, and statistical considerations. Journal of personality and social psychology, 51(6), 1173.

Branch, S., \& Murray, J. (2015). Workplace bullying: Is lack of understanding the reason for inaction. Organizational Dynamics, 44(4), 287-295.

Coetzee, M., \& van Dyk, J. (2018). Workplace bullying and turnover intention: Exploring work engagement as a potential mediator. Psychological reports, 121(2), 375-392.

Charilaos, K., Michael, G., Chryssa, B. T., Panagiota, D., George, C. P., \& Christina, D. (2015). Validation of the Negative Acts Questionnaire (NAQ) in a sample of Greek teachers. Psychology, 6(01), 63.

Dyne, L. V., Ang, S., \&Botero, I. C. (2003). Conceptualizing employee silence and employee voice as multidimensional constructs. Journal of management studies, 40(6), 1359-1392.

Desrayaud, N., Dickson, F. C., \& Webb, L. M. (2018). The theory of bullying conflict cultures: developing a new explanation for workplace bullying. In The Routledgehandbook ofcommunication and bullying (pp. 81-92). Routledge.

D'Cruz, P., \& Rayner, C. (2013). Bullying in the Indian workplace: A study of the ITES-BPO sector. Economic and Industrial Democracy, 34(4), 597-619.

Dedahanov, A. T., Kim, C., \& Rhee, J. (2015). Centralization and communication opportunities as predictors of acquiescent or prosocial silence. Social Behaviorand Personality: an international journal, 43(3), 481-492. 
Fontes, K. B., Alarcão, A. C. J., Santana, R. G., Pelloso, S. M., \& de Barros Carvalho, M.D. (2019). Relationship between leadership, bullying in the workplace and turnover intention among nurses. Journal of nursing management, 27(3), 535-542.

Hobfoll, S. E. (1989). Conservation of resources: a new attempt at conceptualizing stress. American psychologist, 44(3), 513.

Hobfoll, S. E. (2001). The influence of culture, community, and the nested-self in the stress process: Advancing conservation of resources theory. Applied psychology, 50(3), 337-421.

Ismail, S., Romle, A. R., \&Azmar, N. A. (2015). The impact of organizational culture on job satisfaction in higher education institution. International Journal of Administration and Governance, 1(4), 14-19.

Kish-Gephart, J. J., Detert, J. R., Treviño, L. K., \& Edmondson, A. C. (2009). Silenced by fear:: The nature, sources, and consequences of fear at work. Research in organizational behavior, 29, 163-193.

Kell, A. J., Yamins, D. L., Shook, E. N., Norman-Haignere, S. V., \& McDermott, J. H. (2018). A task- optimized neural network replicates human auditory behavior, predicts brain responses, and reveals a cortical processing hierarchy. Neuron, 98(3), 630-644.

Knoll, M., \& Van Dick, R. (2013). Do I hear the whistle...? A first attempt to measure four forms of employee silence and their correlates. Journal of business ethics, 113(2), 349-362.

Keashly, L., \& Neuman, J. H. (2013). Bullying in higher education. Workplace bullying in higher education, 1-22.

Keashly, L. (2021). Workplace bullying, mobbing and harassment in academe: Faculty experience. Special topics and particular occupations, professions and sectors, 221-297.

Kuvaas, B., \&Dysvik, A. (2010). Exploring alternative relationships between perceived investment in employee development, perceived supervisor support and employee outcomes. Human Resource Management Journal, 20(2), 138-156.

Koon, V. Y., \& Pun, P. Y. (2018). The mediating role of emotional exhaustion and job Satisfaction on the relationship between job demands and instigated workplace incivility. The Journal of Applied Behavioral Science, 54(2), 187-207.

Kirkman, B. L., Chen, G., Farh, J. L., Chen, Z. X., \& Lowe, K. B. (2009). Individual power distance orientation and follower reactions to transformational leaders: $\mathrm{A}$ 
cross-level, cross-cultural examination. Academy of management journal, 52(4), 744764.

Keashly, L., \& Neuman, J. H. (2010). Faculty experiences with bullying in higher Education: Causes, consequences, and management. Administrative Theory $\mathcal{E}$ Praxis, 32(1), 48-70.

Knoll, M., \& Van Dick, R. (2013). Authenticity, employee silence, prohibitive voice, and the moderating effect of organizational identification. The Journal of Positive Psychology, 8(4), 346-360.

Lutgen-Sandvik, P., Tracy, S. J., \&Alberts, J. K. (2007). Burned by bullying in the American workplace: Prevalence, perception, degree and impact. Journal of Management Studies, 44(6), 837-862.

Mischel, W., \&Shoda, Y. (1995). A cognitive-affective system theory of personality: reconceptualizing situations, dispositions, dynamics, and invariance in personality structure. Psychological review, 102(2), 246.

Mahmoudi, M., \& Moss, S. E. (2019). Tie institutions' reputations to their antibullying record.Nature, 572(7770), 439-439.

Morrison, E. W., \& Milliken, F. J. (2000). Organizational silence: A barrier to change And development in a pluralistic world. Academy of Management review, 25(4), 706-725.

Magee, C., Gordon, R., Robinson, L., Caputi, P., \&Oades, L. (2017). Workplace Bullyingand absenteeism: The mediating roles of poor health and work engagement. Human Resource Management Journal, 27(3), 319-334.

Pinder, C. C., \&Harlos, K. P. (2001). Employee silence: Quiescence and acquiescence as responses to perceived injustice. In Research in personnel and human resources management. EmeraldGroup Publishing Limited.

Prouska, R., \&Psychogios, A. (2018). Do not say a word! Conceptualizing employee silence in a long-term crisis context. The International Journal of Human ResourceManagement, 29(5), 885-914.

Rai, A., \& Agarwal, U. A. (2017). Linking workplace bullying and work engagement: The mediating role of psychological contract violation. South Asian Journal of Human Resources Management, 4(1), 42-71.

Samnani, A. K. (2013). Embracing new directions in workplace bullying research: A paradigmatic approach. Journal of Management Inquiry, 22(1), 26-36. 
Salin, D., \& Notelaers, G. (2020). The effects of workplace bullying on witnesses: violation of the psychological contract as an explanatory mechanism? The International Journal of Human Resource Management, 31(18), 2319-2339.

Tsuno, K., Kawakami, N., Shimazu, A., Shimada, K., Inoue, A., \&Leiter, M. P. (2017). Workplace incivility in Japan: Reliability and validity of the Japanese version of the modified WorkIncivility Scale. Journal of occupational health, 16-0196.

Verkuil, B., Atasayi, S., \&Molendijk, M. L. (2015). Workplace bullying and mental health: a meta-analysis on cross-sectional and longitudinal data. PloS one, 10(8), e0135225.

Whiteside, D. B., \& Barclay, L. J. (2013). Echoes of silence: Employee silence as a mediator betweenoverall justice and employee outcomes. Journal of business ethics, 116(2), 251-266.

Wang, Y. D., \& Hsieh, H. H. (2013). Organizational ethical climate, perceived Organizationalsupport, and employee silence: A cross-level investigation. Human relations, 66(6), 783-802. 